\title{
DETERMINATIONS OF PERFORMANCE AND MECHANICAL EFFICIENCY IN NORDIC SKIING*
}

\author{
V. NIINIMAA, R. J. SHEPHARD and M. DYON \\ Department of Preventive Medicine and Biostatistics, University of Toronto
}

*Based on a paper presented to the 4th International Symposium on Circumpolar Health, Novosibirsk, October 1978.

\begin{abstract}
Determinants of performance and mechanical efficiency of effort have been made on a group of ten male nordic skiers, all participants in the University of Toronto ski-team. The oxygen intake at the maximum attainable speed of skiing on a level course averaged $\mathbf{8 9 . 6}$ percent of the maximum oxygen intake observed during uphill treadmill running; the latter (average $63.9 \mathrm{ml} . \mathrm{kg}^{-1} \mathrm{~min}^{-1}$ ) may be compared with values $>80 \mathrm{ml} . \mathrm{kg}^{1} \mathrm{~min}^{-1}$ for international competitors. Maximum heart rates and respiratory gas exchange ratios were generally lower during skiing than running, and it is suggested that the maximum oxygen intake attained during skiing is limited by the individual's skill. In support of this the more experienced skiers were able to reach close to 100 percent of the treadmill maximum oxygen intake during level skiing. A multiple regression analysis indicated that the skiing speed sustained over a one-hour period was related to experience of skiing, maximum oxygen intake, and the percentage of body fat. Assuming a dynamic friction coefficient of 0.075 , a drag area of $0.7 \mathrm{~m}^{2}$ and a drag coefficient of 1.0, the gross mechanical efficiency of the university-class skier averaged a little under 20 percent, with a net efficiency of 21.3 percent.
\end{abstract}

\section{INTRODUCTION}

The last several winters have seen a tremendous increase of nordic (cross-country) skiing in North America, probably as a reaction to both the long line-ups and frequent injuries encountered in the downhill sport. The present paper focuses on two aspects of nordic skiing (a) mechanical efficiency and (b) the characteristics of those successful in this type of activity. It is based largely on experience gained in the testing and coaching of average competitors, ten male members of the University of Toronto ski team.

\section{PHYSICAL CHARACTERISTICS}

Physical characteristics are shown in Table I. Height, weight, and grip strength were much as in the normal young Canadian man but lean mass (at $331 \mathrm{~g} / \mathrm{cm}$ ) was above average. The percentage of body fat was below the national average, but nevertheless was higher than reported values for international skiers and other toplevel endurance athletes (Hanson, 1974; Shephard, 1978a, b).

\section{POWER OUTPUT}

The possible speed of sustained skiing depends on the maximum oxygen intake of the individual, the percentage of this maximum that can be developed while skiing, the efficiency of conversion of the released

\section{TABLE I}

Physical characteristics of subjects (mean \pm S.D.).

Age $(\mathrm{yr})$
Height $(\mathrm{cm})$
Weight $(\mathrm{kg})$
Lean mass $(\mathrm{kg})$
Body fat $(\%)$
Grip strength (N)

$21.2 \pm 2.3$

$176.0 \pm 3.4$

$66.6 \pm 3.6$

$58.2 \pm 2.2$

$12.5 \pm 2.5$

$548 \pm 70$

energy into external work, the nature of the terrain, and snow conditions. $\mathrm{VO}_{2}(\max )$ data for treadmill and skiing tests were compared by a standard paired t test.

Table II compares treadmill and skiing $\mathrm{VO}_{2} \max$ values. All subjects reached a true centrally-limited maximum oxygen intake on the treadmill (Shephard et al., 1968). This was shown by a plateauing of oxygen consumption, with appropriate values for maximum heart rate and respiratory gas exchange ratio. As expected, the group was of above average cardio-respiratory fitness, although scores were much less than in international class skiers (Shephard, 1978a, b).

The skiing data were obtained on a $\mathbf{3 0 0}$ metre circular, level track. All participants used "Jarvinen" racing skis - light wooden skis with a tar base and "Swix" wax appropriate to weather and snow conditions (blue, -5 ${ }^{\circ} \mathrm{C}$ to $-7^{\circ} \mathrm{C}$; blue extra $-1{ }^{\circ} \mathrm{C}$ to $-4^{\circ} \mathrm{C}$ ). The subjects 


\section{TABLE II}

A comparison of data obtained on the laboratory treadmill and while making a maximum ski performance.

\begin{tabular}{|c|c|c|c|c|}
\hline Variable & & $\begin{array}{l}\text { Treadmill } \\
\text { data }\end{array}$ & $\begin{array}{l}\text { Skiing } \\
\text { data }\end{array}$ & $\begin{array}{l}\text { Significance } \\
\text { of difference }\end{array}$ \\
\hline \multirow[t]{2}{*}{$\dot{\mathrm{V}} \mathrm{O}_{2} \max$} & $1 / \min$ & $\begin{array}{l}4.24 \\
\pm 0.12\end{array}$ & $\begin{array}{l}3.78 \\
\pm 0.08\end{array}$ & $<0.01$ \\
\hline & $\mathrm{ml} / \mathrm{kg} \cdot \mathrm{min}$ & $\begin{array}{l}63.9 \\
\pm 2.1\end{array}$ & $\begin{array}{l}56.9 \\
\pm 1.5\end{array}$ & $<0.01$ \\
\hline$\dot{v}_{E}$ & $1 / \min$ & $\begin{array}{l}145.2 \\
\pm 4.1\end{array}$ & $\begin{array}{l}123.9 \\
\pm 3.7\end{array}$ & $<0.001$ \\
\hline$f_{h} \max$ & beats $/ \mathrm{min}$ & $\begin{array}{l}196.4 \\
\pm 2.6\end{array}$ & $\begin{array}{l}191.2 \\
\pm 2.8\end{array}$ & $<0.06$ \\
\hline$R$ & & $\begin{array}{l}1.16 \\
\pm 0.02\end{array}$ & $\begin{array}{l}1.07 \\
\pm 0.01\end{array}$ & $<0.001$ \\
\hline$\dot{\mathrm{V}} \mathrm{O}_{2} / \mathrm{f}_{\mathrm{h}}$ & $\mathrm{ml} / \mathrm{b} e \mathrm{et}$ & $\begin{array}{l}21.8 \\
\pm 0.8\end{array}$ & $\begin{array}{l}19.9 \\
\pm 0.6\end{array}$ & $<0.01$ \\
\hline$\dot{\mathrm{V}}_{\mathrm{E}} / \dot{\mathrm{V}}_{2}$ & & $\begin{array}{l}34.5 \\
\pm 0.7\end{array}$ & $\begin{array}{l}32.8 \\
\pm 0.7\end{array}$ & $<0.05$ \\
\hline
\end{tabular}

"warmed up" by skiing for eight min at 80-90 percent of maximum speed, and then continued at maximum speed for $3 \mathrm{~min}$. Heart rates were recorded by a portable cassette tape-recorder, and expired gas was collected in a meteorological balloon during the final minute of activity. The average maximum oxygen intake while skiing was only 89.2 percent of the treadmill figure. Respiratory minute volume, maximum heart rate, respiratory gas exchange ratio and oxygen pulse were also lower on skis than on the treadmill.

\section{TABLE III}

Equation for the prediction of competitive success of skiers. The coefficients were derived by a sequential multiple regression technique. The column $R$ shows the correlation of individual variables with success, the column $\Sigma \mathbf{R}$ the corresponding cumulative multiple correlation.

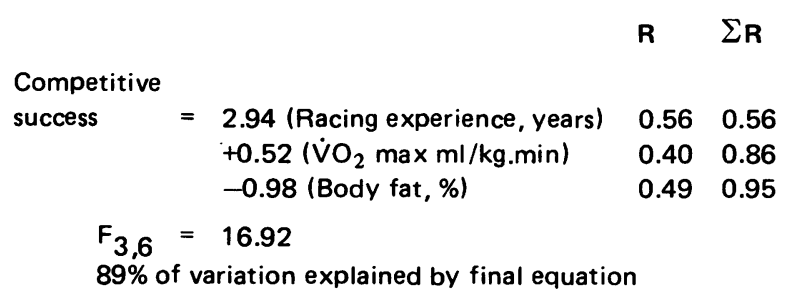

The proportion of the treadmill $\mathrm{VO}_{2}$ max that was realized in the field seemed to depend markedly on skiing experience. One subject who had been racing for six years reached 102.1 percent of the treadmill value. Another with three years racing experience reached 96.6 percent of the treadmill result. In contrast, three fit runners who averaged only 1.3 years of skiing experience reached no more than 81.2 percent of the treadmill figure. Some authors have reported higher values on skis than in the laboratory (Åstrand and Saltin, 1961; Andersen et al, 1962). However, their conclusion rests largely upon use of a bicycle ergometer in the laboratory; it is now well-recognized that the bicycle ergometer underestimates the true maximum oxygen intake (Shephard, 1977).

\section{PREDICTIONS OF SKIING PERFORMANCE}

A serial multiple regression technique was used to examine the determinants of skiing performance. Success was assessed from times in six recent $5-15 \mathrm{~km}$ ski events, relating these results to best times for the competitions in question. The major determinant of speed was skiing experience. However, maximum oxygen intake and the percentage of body fat also contributed significantly to the correlation, the three variables together explaining 89 percent of the variation in performance.

The body fat influenced performance because there is a direct relationship between body mass and ski friction. In the present experiment the subjects wore only a standard light-weight skiing uniform. However, when making a longer journey across the tundra, frictional work would be increased proportionately by any load that had to be carried.

In very long-distance events (more than 2.5 hours), most subjects use only about $\mathbf{8 0}$ percent of their maximum oxygen intake (Hedman, 1957) and the maximum possible speed of movement is set by glycogen stores rather than oxygen transport. However, over intermediate distances there is a close linear relationship between the attained speed and the maximum oxygen intake of the individual. Our subjects were competing for 20-60 minutes, and we estimate that over this period the average competitor used 85 percent of his treadmill maximum oxygen intake. Subjects able to operate at more than 85 percent of $\mathrm{VO}_{2}$ max naturally gained a substantial competitive advantage.

\section{MECHANICAL EFFICIENCY OF SKIING}

Table IV examines the mechanical work performed by the skier. The coefficient of dynamic friction encountered varies greatly with air temperature, radiant heating, freshness of the snow and choice of wax, but a typical value is 0.075 (Penniman and Jerard, 1969; Outwater, 1970). If the subject is moving at a velocity of $250 \mathrm{~m} \cdot \mathrm{min}^{-1}$ and has a laden weight of $72 \mathrm{~kg}$, he will thus carry out frictional work of $13.2 \mathrm{~kg} \cdot \mathrm{min}^{-1}$.

The other main force resisting movement is drag. The dynamic air pressure at a speed of $250 \mathrm{~m} \cdot \mathrm{min}^{-1}$ is about 


\section{TABLE IV}

\section{Example illustrating calculation of net mechanical efficiency of skiing}

$$
\begin{aligned}
& \text { Dynamic coefficient of friction }\left(C_{F}\right)=0.075 \\
& \text { Speed (V) } \quad=250 \mathrm{~m} / \mathrm{min} \\
& \text { Weight }(W) \quad=72.0 \mathrm{~kg} \\
& \text { Frictional work }=V \times W \times C_{F}=1350 \mathrm{~kg} . \mathrm{m} / \mathrm{min} \\
& =13.2 \mathrm{~kJ} / \mathrm{min} \\
& \text { Drag force }(D)=\sim 0.8 \mathrm{~kg} \text { at } 15 \mathrm{~km} / \mathrm{h} \\
& \begin{aligned}
\text { Drag work } \quad=V \times D \quad & =175 \mathrm{~kg} \cdot \mathrm{m} / \mathrm{min} \\
& =1.7 \mathrm{~kJ} / \mathrm{min}
\end{aligned} \\
& \text { Total work }=\text { Friction }+ \text { Drag }=14.9 \mathrm{~kJ} / \mathrm{min} \\
& \text { Energy expenditure }=85 \% \dot{\mathrm{VO}}_{2} \max \\
& =3.61 \mathrm{I} / \mathrm{min}=75.5 \mathrm{~kJ} / \mathrm{min}
\end{aligned}
$$

$1 \mathrm{~kg} \cdot \mathrm{m}^{-2}$. Given a frontal area of $0.7-0.8 \mathrm{~m}^{2}$ and a frontal coefficient of 1.0, the drag force is thus 0.7 $0.8 \mathrm{~kg}$ for a fast-moving skier (Pugh, 1976). Drag naturally increases with a projecting back-pack, or adoption of a more upright posture. In our experiment, drag work amounted to some $1.7 \mathrm{~kg} \cdot \mathrm{min}^{-1}$, about $13 \%$ of the frictional cost. Overall mass and care in waxing are plainly more important considerations for a skier than the streamlining of his back-pack.

The overall mechanical efficiency of level skiing on a prepared trail is thus quite high. Assuming our subjects were using $\mathbf{8 5}$ percent of their maximum oxygen intake, the total oxygen consumption would have averaged 3.6 I. $\min ^{-1}$ equivalent to an energy expenditure of 75.5 $\mathrm{kg} \cdot \mathrm{min}^{-1}$. Assuming further a basal energy expenditure of $5.1 \mathrm{~kg} \cdot \mathrm{min}^{-1}$, the net cost of skiing would be 70.4 $\mathrm{kg} \cdot \mathrm{min}^{-1}$. Since the total work performed was 14.9 kg. $\min ^{-1}$ (Table IV), the gross mechanical efficiency would be just under 20 percent, and the net value about
21.3 percent. This is rather comparable with the 23 percent quoted for the laboratory bicycle ergometer, and a little below the potential value of 25 percent limiting the conversion of chemical into mechanical energy (Shephard, 1977).

The keys to effective skiing are thus quite plain. Work must be minimised by reducing total mass, the coefficient of dynamic friction and drag. There is a small possibility of improving the conversion of chemical into mechanical work. The average citizen can also profit from a development of both the absolute and the usable fraction of his maximum oxygen intake. The multiple regression analysis shows no appreciable influence of lean mass or the grip index of muscle strength upon competition results. This is possibly because any advantage from an increase of muscle force in counteracted by an increase in body mass and thus friction. However, it is also possible that selective testing of individual leg muscles might pick out a gain from developing certain muscle groups that contribute more specifically to skiing performance. Lastly, performance is improved by more than 20 percent if the entire treadmill $\mathrm{VO}_{2} \max$ can be developed on skis.

It is interesting to compare skiing with other potential methods of travel. The energy required to cover a level trail of $15 \mathrm{~km}$ in one hour is approximately equal to that needed if a similar distance is walked on a level treadmill over two hours (Durnin and Passmore, 1967). However, if walking in snow, the energy needed to cover a given distance can be several times greater than that for skiing. Middle-aged subjects approach their $\mathrm{VO}_{2} \max$ if they attempt to maintain a normal walking speed through deep snow.

Snowshoes are normally intermediate in efficiency between walking and cross-country skiing, but in some circumstances (for instance a heavy fall of new and lightly packed snow) they can be the preferred method of transport. It is interesting to note that in their classical paper, Christensen and Högberg set the energy cost of cross-country skiing more than $\mathbf{5 0}$ percent higher than the figure we have estimated for steady performance on a prepared level trail (Christensen and Högberg, 1950). Presumably, their figure reflects the lower efficiency of hill climbing, loss of energy in snow-ploughing descents, and the costs of occasional trail breaking. However, even when crossing uneven terrain, there seems little question that skis are superior to walking once the ground has a moderate snow cover.

\section{REFERENCES}

Andersen, K. L., Elsner, R. E., Saltin, B., and Hermansen L. 1962. "Physical fitness in terms of maximal oxygen intake of nomadic Lapps. Fort Wainwright, Alaska." USAF Arctic Medical Laboratory, Tech.Report AAL TDR 61-53: 1-32. 
Åstrand, P.O. and Saltin, B. 1961. "Maximal oxygen uptake and heart rate in various types of muscular activity." J.Appl.Physiol. 16: 977-981.

Christensen, E. H. and Högberg, P. 1950. “Physiology of skiing." Arbeitsphysiologie 14: 292-303.

Durnin, J. V. G. A. and Passmore, R. 1967. “Energy, work and leisure." Heinemann, London.

Hanson, J. 1974. "Maximal exercise performance in members of the U.S. Nordic ski team." J.Appl.Physiol. 35: 592-595.

Hedman, R. 1957. "The available glycogen in man and the connection between rate of oxygen intake and carbohydrate usage." Acta Physiol.Scand. 40: 305-321.

Outwater, J. O. 1970. “On the friction of skis." Med.Sci.Sports 2: 231-234.

Penniman, R. and Jerard, R. 1969. "On the static and kinetic friction coefficients of various ski surfaces on snow." M.E. Thesis, University of Vermont: 1-31.

Pugh, L. G. C. E. 1976. "Air resistance in sport." Medicine and Sport, Vol. 9: Advances in exercise physiology: 149-164. Ed.: Jokl, E., Anand, R. L. and Stoboy, H. Karger, Basel.

Shephard, R. J. 1977. "Endurance Fitness." University of Toronto Press: 136.

Shephard, R. J., Allen, C., Benade, A. J. S., Davies, C. T. M., DiPrampero, P. E., Hedman, R., Merriman, J. E., Myhre, K., and Simmons, R. 1968. "The maximum oxygen intake. An international reference standard of cardiorespiratory fitness." Bull.WHO 38: 757-764.

Shephard, R. J. 1978a. "Human physiological work capacity." Cambridge, London.

Shephard, R. J. 1978b. "The Fit Athlete." Oxford University Press, London.

\section{MEETINGS OF OTHER ORGANISATIONS}

\section{FIRST INTERNATIONAL COURSE ON PHYSIOLOGICAL CHEMISTRY OF EXERCISE AND TRAINING October 1st-4th, 1979}

This course, under the aegis of UNESCO Research Group on Biochemistry of Exercise, will be held in FIUGGI TERME, Italy, from October 1st - 4th, 1979. Topics include:

\section{Muscular contraction \\ Regulation of Metabolism \\ Biological fuel utilisation \\ Electrolytes \& Hormone regulation \\ Ultrastructure of muscle \\ Exercise in extreme environments \\ Anaerobic glycolysis}

The official language will be English. The fee is $\$ 200$ U.S., and includes full board and lodging from September 30th, bus transport from Rome, $\mathbf{4 0}$ miles away, and social events. English/Italian simultaneous translation is foreseen.

PRELIMINARY APPLICATIONS should be made by February 28th, 1979, to the Congress Secretariat: Ente Fiuggi S.p.A., Via Pinciana 25, 00198 ROMA, Italy.

A very limited number of application forms are available from BASM Treasurer, Dr. H. E. Robson, 39 Linkfield Road, Mountsorrel, LOUGHBOROUGH, Leicestershire. 